\title{
Productive Housing: Spatial Structuring and Social Division in Urban Centers
}

\author{
DANIEL ESGUEVILLAS \\ Universidad Camilo José Cela
}

\author{
LUZ CARRUTHERS \\ Universidad Politécnica de Madrid
}

\begin{abstract}
This paper examines the way in which Airbnb dynamics are changing spatial and social conditions in urban centers. A comparative study of the situation in three important global metropolis-New York, London and Barcelona-provides an approach to analyzing how policymakers struggle to control the accelerated expansion of the short-term rental housing platform, under the scrutiny of the public. It aims to foster a broader understanding of the impact of the sharing economy in the realm of housing, in a context of economic globalization and decline of the welfare state, where advances in technology meet with sociological and generational shifts in behavior.
\end{abstract}

In his insightful 1995 text 'What Ever Happened to Urbanism?' Rem Koolhaas criticizes the failure of architecture and urbanism to design cities after modernism, precisely at a moment when rapid urbanization everywhere begins posing accelerated challenges to urban areas, and when urbanists are left to one side in an endless world race for growth and concentration of people and power. "If there is to be a new urbanism," he writes, "it will no longer be about" "the imposition of limits." ${ }^{1}$ More than twenty years later, the digital revolution has erased global boundaries and innovative business models expand, mostly across urban centers, with disruptive services related to the increasing flows of capital and people between cities. The appearance of the sharing economy is not only connected with advances in technology but also with sociological and generational shifts in behavior, especially after the gradual yet consistent decline of the welfare state following the financial crisis of 2008. In this context of stressed middle classes, new possibilities arise for a productive use of housing, beyond capital investment or workplaces, made possible by the platform economy. Boundaries between life, work and commerce disappear while housing is rediscovered as a rental asset. On one hand, it becomes safe and simple to earn vital extra income in a very flexible and customized way. On the other, unique and personal living experiences can be enjoyed at competitive rates.

It all started ten years ago when Airbnb co-founders rented out air mattresses in their own San Francisco apartment to raise money from local conference-goers in one of the cities with highest rent prices in the world. It has now become a startup valued at over $\$ 30$ billion $^{2}$ and present in the main touristic destinations in almost 200 countries. In the meantime, the utopian vision of urban cooperation has turned into political turmoil as city authorities set out restrictions and global concern grows over driving up rents and broken communities. This paper examines how Airbnb dynamics have altered spatial structuring and social division in urban centers. Specifically, it analyzes the way policymakers in global metropolis like New York, London or Barcelona, where there is an enormous strain on rental prices, attempt to confine the accelerated expansion of the platform amidst scrutiny from local dwellers and businesses. It aims to foster a broader understanding of contemporary urban condition, where digital and physical spaces converge, lines between public and private blur, local and global processes interact, and topdown and bottom-up concepts meet, from a spatial and social perspective. It seeks to explore opportunities for developing new approaches to designing and planning today's uncertain cities, further than the use of limits.

\section{INTRODUCTION}

The contemporary urban condition implies both a deep transformation of cities in a multi-scalar way and the crisis of traditional urban theories, as stated by architect Rem Koolhaas in 1995 in 'What Ever Happened to Urbanism?', where he confirms urban uncertainty and "the death of urbanism." ${ }^{3}$ The digital technologies are transforming the urban realm. The sharing economy is built upon the possibilities of the internet to efficiently match user needs with appropriate goods and services in a consumer utopia that has erased the limits between digital and physical experiences. Its appearance is linked, on one side, to the gradual yet consistent decline of the welfare state in western countries after the financial crisis of 2008. Middle classes are facing difficulties to make ends meet in contemporary global cities as the cost of life is increasing beyond salaries and the platform economy offers a way to earn an extra income with limited obligations. On the other, it is connected with sociological and generational shifts in behavior on digital identity and user experience. The digital revolution turns housing into a service. This new version of productive housing differs from 'solid' activities like renting or investing in its 'liquidity' ${ }^{4}$ made of multiplicity, temporariness, transformation, lightness, immediateness and flexibility. It is a conceptualization that is consistent with the increasing urban mobility for tourism and business, fulfilling the demands for domestic experiences adapted to the user's needs.

A decade ago, Brian Chesky and Joe Gebbia co-founded Airbnb after renting out air mattresses in their own San Francisco apartment to raise money from local conference-goers ${ }^{5}$ in 


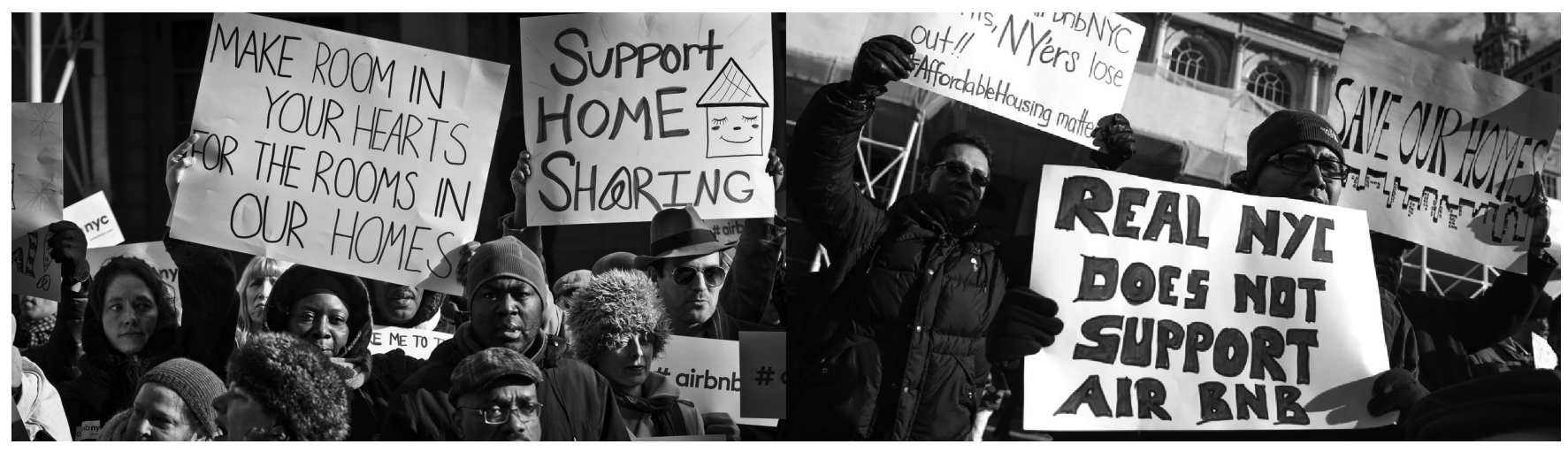

Figure 1: New Yorkers rally in favor and against Airbnb after bill was signed regulating short-term rentals, 2016, Reuters.

one of the cities with highest rent prices in the world. A success story, their startup is now valued at over $\$ 30$ billion and is present in the main touristic destinations of almost 200 countries, including all global cities. The platform connects hosts listing rooms or houses with potential guests, all of them identified with a profile and picture to reinforce the sense of community. Airbnb keeps and guarantees the economic flows as the intermediary in their transaction, charging a fee. Attractive slogans as "live like a local" or "belong anywhere" capture its distinctive philosophy ${ }^{6}$ versus hotels and touristic apartments. The listings become privately owned public spaces for the consumption of a desired domesticity. The rapid growth and urban expansion of Airbnb is a visible spatial component of a social transformation of the way we live and work in contemporary cities. Designed to attract the middle classes, it is accused of contributing to the gentrification of urban centers as places of consumption and to the displacement of local communities by travelers and tourists. ${ }^{7}$ Due to its current significance, it can be related to the major spatial restructuring taking place in the urban centers of the global cities in coalescence with real estate interests, and to the social division derived from the moving out of relatively poorer populations. ${ }^{8}$

After the difficulties of the startup to regulate itself and the absence of detailed data about its activity, city councils started to design policies to stand for the local communities and the existing urban fabric. Specifically, town halls are concerned with the lack of sufficient affordable housing, exacerbated by its moving from long-term to short-term rentals, ${ }^{9}$ and with the displacement of local culture and its substitution with tourists and their global trends. Nevertheless, some of the benefits of Airbnb include relevant economic revenue for the city and for those hosts under financial struggle, as well as cultural exchanges that promote the internationalization and the image of the city. At the start, hotels feared that the platform would reduce their market share, but time has proved that both services tend to be complementary ${ }^{10}$ and that the whole market for travelers has increased, supported by cheaper flights and transportation. This paper examines how Airbnb dynamics have altered spatial structuring and social division in three significant global metropolis-New York, London and Barcelona-ranking within the ten biggest markets of the platform. Its comparative analysis seeks to contribute to a better understanding of the opportunities for an enhanced cooperation between Airbnb and local governments.

\section{A COMPARATIVE STUDY OF THE SITUATION IN NEW YORK, LONDON AND BARCELONA}

New York City is the third biggest market of Airbnb with almost 50,000 listings of houses and bedrooms, about fifty percent each ${ }^{11}$. Soaring costs of living in the city make it a good option to rent your house or bedroom for the time that you are not there and subsidize your travels, or to keep your home renting out a room and benefit from cultural exchanges. This is the option of those hosts with low and moderate incomes, and can be regarded as beneficial home sharing. A different case is when the listings are not primary residences and there is a suspicion that the properties might have been subtracted from the long-term rental market, thus increasing the cost of affordable housing in the city. A recent general study ${ }^{12}$ estimates that the raises in Airbnb listings contribute to the increase in rental rates and house prices, and that there is a minor effect in areas with larger home ownership rates. Listings in New York rose sharply in the past five years. According to a specific report from an urban research group, ${ }^{13}$ over a quarter of the total revenue is earned by the minority of hosts that hold multiple listings and there is an unequal distribution of host revenue between the top listings and the majority of hosts, attracting interest from commercial operators. Airbnb is concentrated in the central districts, particularly in South-West Manhattan and Williamsburg, but its area of influence is expanding into the rest of Manhattan and Brooklyn, displacing people with lower incomes, immigrants and minorities further away in Brooklyn and Queens. ${ }^{14}$ The gentrification is pushing the boundaries and balancing tourism across the territory. The relationship between Airbnb and the regional and local authorities of New York has not been cooperative until recently. In 2010 


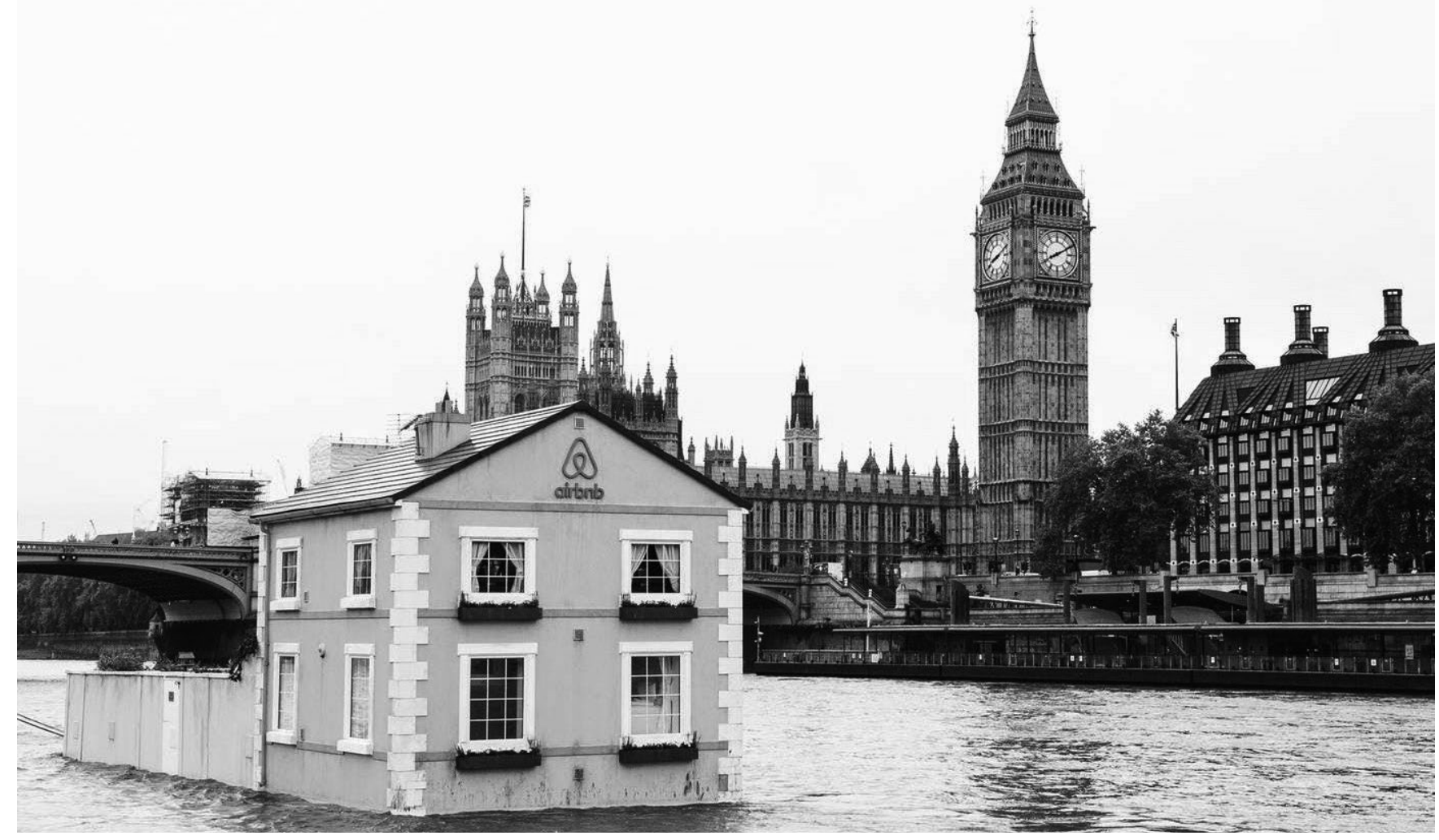

Figure 2: Airbnb floats a house down the river Thames to celebrate rules deregulating short-term rentals in London, 2015, Airbnb.

New York State Multiple Dwelling Law (MDL) prohibited short-term rentals of fewer than thirty days in buildings with three or more units, unless the owner is present. The regulation renders illegal a number of Airbnb transactions and excludes classical home sharing options like while being on vacation, even if the housing contract allows. The law is difficult to enforce and three years later Airbnb declined to provide specific data on hosts to New York State Attorney General. ${ }^{15}$ In 2016 New York State Governor signed a bill to ban the advertising of rentals not complying with the MDL, and established fines on hosts of up to $\$ 7,500$ per listing, over the median annual earnings from home sharing in the city. ${ }^{16}$ Airbnb filed and settled a lawsuit to clear that only the hosts were accountable for the information they displayed in the platform. Amid concerns from the hosts, commercial operators were the primary target of the law, according to the authorities ${ }^{17}$. After the turmoil, Airbnb proposed the council a tax partnership and in 2017 implemented a 'One Host, One Home ${ }^{18}$ policy to confront growing criticism.

Compared to New York, there has been little reaction against the platform in London, probably because of the terrible landlords and housing costs. With a number of listings and a share of houses similar to New York, the main difference rests in the bigger proportion of commercial operators disguised as hosts. ${ }^{19}$ In 2015 the Deregulation Act was approved and the temporary visitor accommodation rules were relaxed: it became legal to list an entire home up to ninety days a year, without a permission. The legislation acknowledged "the development of the internet and changes in the way that people want to use their homes."20 However, it was still necessary to follow the terms of signed contracts and insurance policies. Yet the enforcement of the law was nearly impossible because town halls lacked data and resources to control the number of days. Airbnb came under criticism as certain listings were advertised for more than ninety days without a planning permission, so in 2017 it started to cooperate with London city council and automatically limit entire home listings to ninety days per year, ${ }^{21}$ unless hosts confirm that they have the required planning permission. In parallel, the British Government encouraged in 2016 home sharing by creating tax advantages: hosts could receive up to $£ 7,500$ a year tax-free if they provided furnished accommodation in their main home.

According to a research paper ${ }^{22}$, early adopters of Airbnb hosting in London were young and ethnically diverse residents in central neighborhoods, maybe students. Then it expanded to areas dominated by home owners, some of which under economic difficulties. As time passed by, central areas became consistently less predominant and low income hosts with rented houses, more important. This vision supports Airbnb statements about its spreading of guests and benefits spatially and socially. Airbnb demand is always hard 


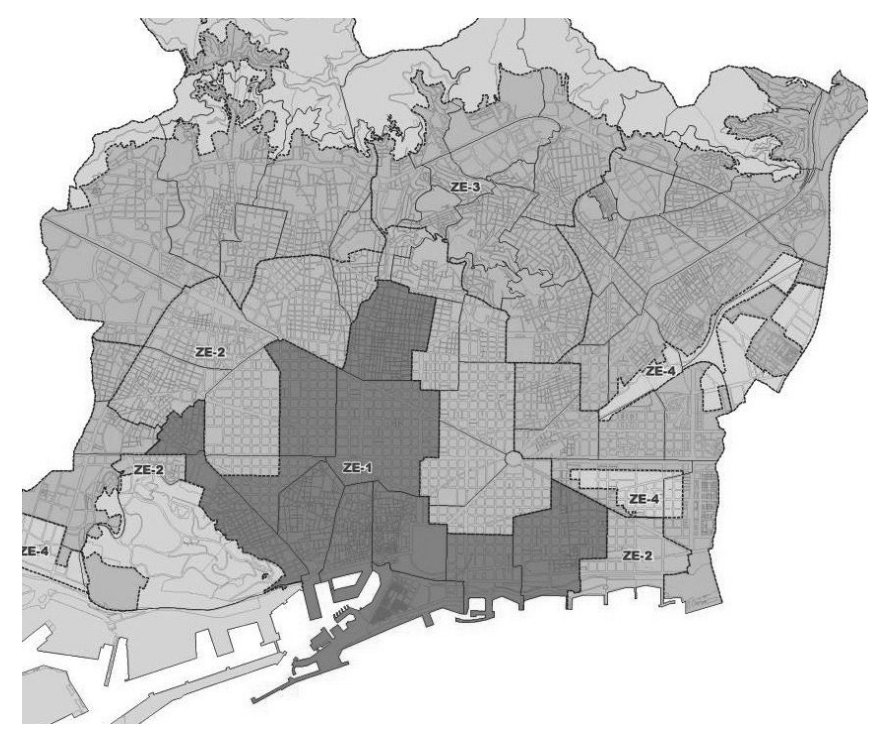

Figure 3: Spatial zoning, Special Urban Planning for Touristic Accommodations (PEUAT), 2017, Barcelona City Council.

to estimate as no respective data is issued by the platform, so the only proxy are user reviews, quite significant in their community. According to them, the closer to the center, the higher the demand is ${ }^{23}$ But the spread of the hosts across the city contributes to the sustainability of its tourism. With twenty million international tourists last year in a city of fourteen million, Airbnb serves to its multiculturalism.

Opposite to the deregulation in London, Barcelona has intensively legislated short-term rentals and hotels, including Airbnb, due to the deteriorated coexistence between tourists and locals in downtown. Unlike New York or London, the Mediterranean city has a much smaller urban area of five million inhabitants with a very concentrated center, receiving last year close to ten million international tourists, ${ }^{24}$ of which almost three million come in cruise ships and therefore punctually collapse downtown. It is in this area that there is a concentration of short-term rentals, ${ }^{25}$ whereas the local population has declined. The density of tourism raises concerns about losing local identity and culture. Specifically, the situation has worsened in Barceloneta, the ancient fishers' village by the beach, where young tourists misbehave and party, which has spurred graffiti and even demonstrations against tourism..$^{26}$ Besides, after the financial crisis of 2008 there has been in Spain an internal devaluation of salaries and prices, which has boosted international tourism and augmented the need of extra incomes for the population. In the past three years, rents have risen much faster than salaries in the city.

When Airbnb started in 2012 in Barcelona, its regional authorities already had a register of short-term rentals and it was illegal not to display the license in the advertisements. In 2014 the regional government fined Airbnb, for the first time in Europe, $€ 30,000$ for breaking this law. Although the startup accepted to pay, it appealed in court and two years later the penalty was annulled "on the grounds that there is a legal vacuum regarding the regulation of the sharing economy." 27 In the meanwhile, Barcelona city council charged Airbnb twice in 2015, $€ 30,000$ each time, for the same reason and in 2016 incremented the fine to $€ 600,000$ as the platform continued to display illegal short-term rentals. ${ }^{28}$ Besides, conscious of the social divisions caused by tourism, the city council established a temporary blanket ban on any kind of new touristic property, including short-term rentals and hotels, paralyzing all real estate related projects. The prohibition ended in 2017 when a new Special Urban Planning for Touristic Accommodations (PEUAT) ${ }^{29}$ was approved. It applies a spatial zoning to the city and divides it into three big zones with a fourth one for dismissed areas under regeneration. In the first one, corresponding to the city center, a shrinking policy is decided and no new or extension projects are allowed, so that the touristic properties decrease. In the second one, the touristic capacity is to be maintained, whereas in the third one, sustainable development is envisioned and new touristic properties can compensate those eliminated in the central area.

This combative policy has faced strong opposition from the hotel sector, while it has led to collaboration with Airbnb. During the past two years, the city council reinforced its campaign against illegal short-term rentals by the raise of the number of inspectors from 20 to 110, the digital monitoring of platforms like Airbnb to detect illegalities, and the start of a hotline where people could check and report illegal short-term rentals in an anonymous and easy way..$^{30}$ As a result, Airbnb was asked to retire 1,000 illegal listings in 2017 and 2,500 in 2018, what eventually happened in the midst of a negotiation process between the platform and the city council, which ended up last month in an agreement. ${ }^{31}$ Airbnb has implemented a new tool in its website so that new listings have to specify whether they are registered or not and agree to share their personal data with local and regional authorities. Moreover, a 'One Host, One Home' policy has been put in practice in downtown in the case existing hosts do not agree to share their personal data. ${ }^{32}$ The cooperation between Airbnb and the city council has succeeded in reducing considerably the number of illegal short-term rentals, and has contributed to an increase in transparency around the Airbnb community in Barcelona.

\section{DISCUSSION AND CONCLUSIONS}

After comparing the situation in the three cities studied, we observe that Airbnb cooperation is critical to regulate its activity. The platform could be a very powerful tool for city councils to obtain information in real time about the distribution of tourists in their neighborhoods and additional data to guide policy design. On the other hand, local rules about home sharing and short-term rentals need to be clear. This is the case in the deregulated London and the 

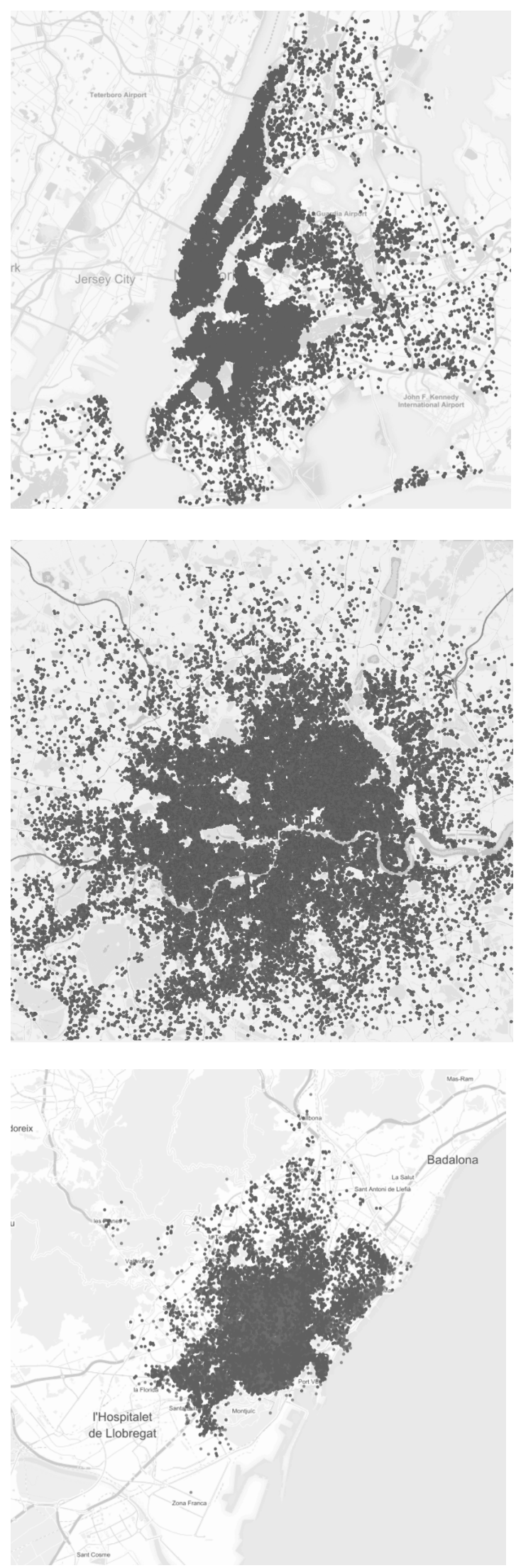

Figure 4: Estimated activity of Airbnb in New York, London and Barcelona,2018, Inside Airbnb. extremely legislated Barcelona. Instead, in New York there is growing pressure to update MDL legislation and allow short-term whole rentals for less than thirty days. In all cities, Airbnb has come to collaborate by providing certain control from the platform: the 'One Host, One Home' policy both in New York and Barcelona, and the verification of permissions in London and Barcelona. Both measures contribute to tackle the problem of the housing conversion from long-term to short-term rentals, which derives in the increasing of rents. Barcelona is the most determined to put an end to this issue, as there is popular resentment against massive tourism. The city council has implemented several restrictive policies: not issuing new licenses for short-term rentals since 2015, intensively pursuing illegal short-term rentals and effectively planning to reduce their presence in downtown. London has a flexible yet efficient limit: no more than ninety days a year, enough to prevent the conversion from happening. Contrary to New York, where the law is severe but difficult to enforce, so the issue persists.

Regarding the right to housing as a service, London would be the best place as the authorities understand that the platform economy has transformed the way we live and deal with domestic experiences. Hosts can rent out their homes the whole summer or every weekend in a year, even with tax advantages. Opposite would be Barcelona where home sharing is restricted to existing licenses before 2015, and authorities have essayed to fine Airbnb, not recognizing that the platform economy is different to traditional touristic rentals and limiting the rights of people to become hosts. New York would be half way between acknowledging the right to home sharing and pursuing it, an uncertain situation where hosts can rent out their houses but are exposed to fines. In each of the three cities studied, the sharing economy raises concerns about increasing gentrification in urban centers. As a result of the spreading of Airbnb across the metropolitan areas of New York and London, rents tend to be higher and there is a displacement of minorities and people with lower incomes. At the same time, visitors extend in the territory and reduce the pressure on the city centers. Instead, the minor urban scale of Barcelona concentrates short-term rentals and visitors in downtown, leading to growing social unrest connected to soaring rents and intensive real estate gentrification. Hence the city council has designed a comprehensive set of spatial and social policies to support local identity: blanket ban, targeted restrictions, zoning, licensing and taxing.

It is important to underline that home sharing responds to socioeconomic changes in our behavior on digital identities and around 'accessing' versus 'possessing', as well as to the need of different domestic experiences in urban mobility and of extra incomes in a context of rising costs of living in the global metropolis. Airbnb cannot be considered the direct cause of housing problems and rent increases, yet it can intensify these issues unless the conversion from 
long-term to short-term rentals is analyzed and regulated. In this sense, commercial hosts listing multiple properties can pose a problem as they do not fit in the home sharing philosophy and might distort the housing market. Besides, the concentration of short-term rentals in a specific area should be avoided to preserve urban identity and culture. Therefore, real cooperation of Airbnb with city councils is essential for the sustainable coexistence of local residents and visitors. To favor this social inclusion and mitigate the negative effects of gentrification, passive policies like bans or restrictions are not sufficient, and active social housing policies might be developed in partnership with Airbnb, who can also provide valuable and real-time data to inform planning decisions. Home sharing is a more sustainable and environmentally conscious way of traveling in comparison to hotels, so authorities could develop smarter policies to promote it and, at the same time, reinforce its responsible and responsive use to prevent social crisis with the locals. Cities cannot lose their identity in the flows of international urban mobility, and housing as a service can help to keep the domesticity and culture of places if adequate, clear and flexible regulation and cooperation with the industry is envisioned.

\section{ENDNOTES}

1. Rem Koolhaas, "What Ever Happened to Urbanism?" in $S, M, L, X L$, ed., O.M.A. (New York: The Monacelli Press, 1997), 969.

2. Airbnb was reportedly valued at $\$ 31$ billion in its last round of funding in March 2017.

3. Koolhaas, "What Ever Happened to Urbanism?," 967.

4. Zygmunt Bauman, Liquid Times: Living in an Age of Uncertainty (Cambridge, UK: Polity Press, 2007).

5. Warren Berger, A More Beautiful Question: The Power of Inquiry to Spark Breakthrough Ideas (New York: Bloomsbury, 2014), 88.

6. Ben Davis, "10 Examples of Great Airbnb Marketing Creative," Econsultancy, 2016, https://econsultancy.com/ blog/68225-10-examples-of-great-airbnb-marketing-creative.

7. Dayne Lee, "How Airbnb Short-Term Rentals Exacerbate Los Angeles's Affordable Housing Crisis: Analysis and Policy Recommendations," Harvard Law \& Policy Review 10, no. 1 (2016), http://harvardlpr.com/wp-content/ uploads/2016/02/10.1_10_Lee.pdf.

8. Joanne Massey, "The Gentrification of Consumption," Sociological Research Online 10, no. 2 (2005), http://www.socresonline.org.uk/10/2/massey.html.

9. Kyle Barron, Edward Kung, and Davide Proserpio, "The Sharing Economy and Housing Affordability: Evidence from Airbnb," SSRN (2018), https://ssrn.com/ abstract=3006832.

10. Jonathan Dell et al., "The Impacts of the Peer-to-Peer Platform on the raditional Lodging Industry," Journal of Applied Business and Economics 19. 7 (2017) http://www.na-businesspress.com/JABE/JABE19-7/ DellJ_19_7_.pdf.

11. Murray Cox, "New York City," Inside Airbnb, 2018, http://insideairbnb.com/ new-york-city/.

12. Barron, Kung, and Proserpio, "The Sharing Economy and Housing Affordability," 6

13. David Wachsmuth et al., The High Cost of Short-Term Rentals in New York City (New York: McGill University, 2018).

14. Wachsmuth et al., 37.

15. Eric Schneiderman, ed., Airbnb in the City, report from the New York State Attorney General, 2014, p. 4.
16. The median host revenue per year is $\$ 6,401$. See the Airbnb Citizen official website, accessed 2018, https://www.airbnbcitizen.com/new-york-city/.

17. Joanna Walters, "Something in the Airbnb: Hosts Anxious as New York begins Crackdown," The Guardian, February 12, 2017.

18. "July Update on One Host, One Home: New York City," Airbnb Citizen official website, accessed 2018, https://www.airbnbcitizen.com/ julyupdate-on-one-host-one-home-new-york-city-2/.

19. $40,9 \%$ of multi-listings. See Murray Cox, "London," Inside Airbnb web database, accessed 2018, http://insideairbnb.com/london/.

20. "Explanatory Note 210," Sections 44/45, Deregulation Act 2015, http://www. legislation.gov.uk/ukpga/2015/20/notes/division/5/46.

21. "I rent out my home in London. What short-term rental laws apply?" Help Centre page on Airbnb official website, accessed 2018, https://www airbnb. co.uk/help/article/1340/i-rent-out-my-home-in-london--what-short-termrental-laws-apply.

22. Giovanni Quattrone et al.," "Who Benefits from the 'Sharing' Economy of Airbnb?" in Proceedings of the 26th International ACM Conference on World Wide Web (New York: Association for Computing Machinery, 2017).

23. Cox, "London."

24. "Tourism in Barcelona," Statista website, accessed 2016, https://www. statista.com/topics/4156/tourism-in-barcelona/.

25. Cox, "Barcelona," Inside Airbnb web database, accessed 2018, http:// insideairbnb.com/barcelona/

26. Robert Plummer, "Are Tourists Still Welcome after Protests?" BBC News, August 17, 2017.

27. Abigail Miller, "Airbnb Escapes Fine in Spain for Advertising Lodgings that Didn't Have Permits," Daily Mail, December 13, 2016.

28. James Badcock, "Barcelona to Fine Airbnb and HomeAway $€ 600,000$ Each for Offering 'llegal' Accommodation," The Telegraph, November 24, 2016.

29. “Plan Especial Urbanístico de Alojamientos Turísticos (PEUAT)," Barcelona's Town Hall, 2017.

30. "Flat Detector," Barcelona's Town Hall, City of Barcelona official website, 2018, http://meet.barcelona.cat/habitatgesturistics/en/.

31. Feargus O'Sullivan, "Barcelona Finds a Way to Control Its Airbnb Market," CityLab, June 6, 2018.

32. "Airbnb Launches New Responsible Home Sharing Tool in Barcelona and Catalonia," Airbnb Citizen official website, accessed 2018, https://www. airbnbcitizen.com/airbnb-launches-new-responsible-home-sharing-tool-inbarcelona-and-catalonia/. 